\title{
XX Reunión Anual de Etnología - RAE 2006
}

23 al 26 de agosto 2006

\section{Elizabeth Torres}

\section{OpenEdition \\ Journals}

\section{Edición electrónica}

URL: http://journals.openedition.org/bifea/4706

DOI: 10.4000/bifea.4706

ISSN: 2076-5827

Editor

Institut Français d'Études Andines

\section{Edición impresa}

Fecha de publicación: 1 mayo 2006

Paginación: 231-233

ISSN: 0303-7495

Referencia electrónica

Elizabeth Torres, "XX Reunión Anual de Etnología - RAE 2006 », Bulletin de l'Institut français d'études andines [En línea], 35 (2) | 2006, Publicado el 08 mayo 2006, consultado el 06 diciembre 2020. URL : http://journals.openedition.org/bifea/4706 ; DOI : https://doi.org/10.4000/bifea.4706

\section{(c)}

Les contenus du Bulletin de l'Institut français d'études andines sont mis à disposition selon les termes de la licence Creative Commons Attribution - Pas d'Utilisation Commerciale - Pas de Modification 4.0 International. 
23 al 26 de agosto 2006

La vigésima Reunión Anual de Etnología es un orgullo Institucional y su denominativo en el año 2006: «ITINERANCIAS IDENTITARIAS. Permanencias y Cambios Sociales», muestra la realidad que hoy hace noticia en el mundo entero. 
Transitar o trasladarse, son actividades presentes en la humanidad desde el principio de los tiempos. Sin embargo, estos procesos van ligados a nuevos conocimientos y experiencias, a partir de las cuales, los grupos humanos van desarrollando una serie de posibilidades creativas, que conviven junto a situaciones de discriminación, racismo, y dinámicas de conflicto, que en muchos casos desembocan en procesos violentos.

En nuestro país por la baja oferta laboral ya son muchos años que se generan flujos migratorios, tanto al interior del territorio, dirigidos hacia los valles y los llanos, como al exterior, a países limítrofes y continentes lejanos que se convierten en contenedores de grupos familiares que poco a poco van configurando grupos de residentes bolivianos.

Estos procesos llevan a que al interior del territorio boliviano se vayan dibujando nuevos límites y las identidades sufran fragmentaciones continuas. «Nuevas» naciones circulan en el imaginario de los habitantes y el territorio se convierte en una metáfora que solo puede ser comprendida desde la Diversidad Cultural.

Sin embargo al interior de estos «nuevos límites», las representaciones sociales transitan encontrando nuevos referentes en el imaginario de los grupos de llegada, mientras que los grupos de acogida «re-componen» sus universos simbólicos. Lo antiguo y lo nuevo, junto con lo propio y lo extraño se cruzan y a partir de nuevos procesos, intentan pintar nuevas fronteras.

Estos y muchos más, han sido los análisis que han congregado y motivado los cuatro días de encuentro y reflexión.

Varios seminarios se llevaron a cabo:

En el seminario Arqueología y Arte Rupestre se abordaron temáticas como la del arte rupestre en Puno; investigaciones específicas en sitios arqueológicos como el de Khokho Wankani en Bolivia; la mirada de una arqueología social en Latinoamérica; y finalmente el apoyo de las técnicas de la arqueología en el estudio, análisis e interpretación de la arquitectura colonial.

En el de Antropología Histórica, las exposiciones estuvieron principalmente centradas en la historia, etnohistoria y la lingüística. Este seminario se vio enriquecido con el desarrollo de una mesa redonda: «La Asamblea Constituyente de 1938: Viejos problemas, nuevas miradas», que contó con la asistencia de muchos historiadores.

En el seminario Antropología Social y/o Cultural se organizaron, por la diversidad de trabajos, las disertaciones desde la siguiente perspectiva: antropología económica, con investigaciones tanto en las comunidades como en las urbes; antropología política, haciendo énfasis en las nuevas concepciones del Tawantinsuyo y su trascendencia en las propuestas para la Asamblea Constituyente; antropología urbana, tocando más que nada la problemática juvenil; antropología de género, vista en las comunidades; antropología educativa, desde varios ángulos, incluyendo la actual polémica de la descolonización hasta la educación especial para niños de capacidades especiales; antropología médica, abordada desde el paciente; antropología de la religión, vista como ritualidad; y la identidad tocada desde distintos ángulos y etnias.

El seminario Culturas Populares contó con la participación de expositores de diversos sectores sociales, así como de distintas regiones. Los trabajos se agruparon en: trabajos que reflejan la vivencia cotidiana y trabajos académicos, como resultado de procesos de investigación y reflexión, sobre tópicos de culturas populares. Entre los temas tratados estuvieron: Fiestas Patronales; Medios de comunicación que dan cobertura a «lo popular» como expresión de masas; Turismo y su relación con las comunidades; Simbolismo y Religiosidad de los atuendos festivos; Culinaria «tradicional»; Danzas; Música, interpretación e Instrumentos. En esta mesa se contó con la participación de expositores de Chile, Argentina, Inglaterra y Bolivia.

El seminario Itinerancias Identitarias: permanencias y cambios sociales permitió escuchar ponencias muy diversas, a pesar de que todos los expositores tomaron en cuenta los procesos de itinerancia relacionados con la identidad. La perspectiva en la que situaron estos contenidos marcó la diferencia de uno a otro.

Se tocaron temas relacionados con el medio ambiente, las «subculturas» en El Alto, así como los relacionados con el «cambio político» y las movilizaciones indígenas-populares. La Población 
alemana, judía y francesa en Arequipa y la Ruta del pisco en el valle de Vítor, fueron temas expuestos por expositores que llegaron del Perú.

Se reflexionó también acerca de las identidades dispersas en Bolivia y sobre la pregunta de si existe una identidad nacional. Dos ponencias tocaron el tema relacionado con la salud. Uno desde la itinerancia kallawaya, entre lo moderno y lo tradicional y otro a partir de la pregunta $\dot{E} E s$ posible un diálogo de saberes? (entre la medicina occidental y la andina).

El argentino Omar Geréz planteo una reflexión en torno a los ingenios azucareros del norte de su país y los movimientos migratorios transnacionales entre Bolivia y Argentina. Discriminación, estatus, marginalidad, poder económico y hegemonías políticas, fueron conceptos que sirvieron para dar cuerpo a la ponencia del investigador.

La ecuatoriana Alicia Torres planteó también el tema de las migraciones transnacionales, en este caso relacionado con la comunidad otavaleña del Ecuador. Patrones de comportamiento, círculos sociales, estatus y matrimonios exogámicos ilustraron la actualidad de los procesos sociales y sus cambios en esta comunidad del Ecuador.

Este seminario fue realzado con dos documentales, cada uno de más de 30 minutos, producidos por la Asamblea Permanente de Derechos Humanos, a propósito de los dos millones de migrantes que viven en la Argentina. 